Walter, R.K., P. Lin, M. Edwards, and R.E. Richardson (2011), Investigation of factors affecting theaccumulation of vinyl chloride in polyvinyl chloride piping used in drinking water distributionsystems, Water Research (45), 8, doi: 10.1016/j.watres.2011.02.016.

\title{
Investigation of factors affecting the accumulation of vinyl chloride in polyvinyl chloride piping used in drinking water distribution systems
}

\author{
Ryan K. Waltera, Po-Hsun Lina, Marc Edwards ${ }^{\mathrm{b}}$, Ruth E. Richardson ${ }^{\mathrm{a}}$ \\ a School of Civil and Environmental Engineering, Cornell University, Ithaca, NY, USA \\ ${ }^{\mathrm{b}}$ Department of Civil and Environmental Engineering, Virginia Polytechnic Institute and State University, Blacksburg, VA, USA
}

A B S T R A C T

Plastic piping made of polyvinyl chloride (PVC), and chlorinated PVC (CPVC), is being increasingly used for drinking water distribution lines. Given the formulation of the material from vinyl chloride (VC), there has been concern that the VC (a confirmed human carcinogen) can leach from the plastic piping into drinking water. PVC/CPVC pipe reactors in the laboratory and tap samples collected from consumers homes $(n=15)$ revealed vinyl chloride accumulation in the tens of $n g / L$ range after a few days and hundreds of $n g / L$ after two years. While these levels did not exceed the EPA's maximum contaminant level (MCL) of $2 \mathrm{mg} / \mathrm{L}$, many readings that simulated stagnation times in homes (overnight) exceeded the MCL-Goal of $0 \mathrm{mg} / \mathrm{L}$. Considerable differences in VC levels were seen across different manufacturers, while aging and biofilm effects were generally small. Preliminary evidence suggests that VC may accumulate not only via chemical leaching from the plastic piping, but also as a disinfection byproduct (DBP) via a chlorine-dependent reaction. This is supported from studies with CPVC pipe reactors where chlorinated reactors accumulated more VC than dechlorinated reactors, copper pipe reactors that accumulated VC in chlorinated reactors and not in dechlorinated reactors, and field samples where VC levels were the same before and after flushing the lines where PVC/CPVC fittings were contributing. Free chlorine residual tests suggest that VC may be formed as a secondary, rather than primary, DBP. Further research and additional studies need to be conducted in order to elucidate reaction mechanisms and tease apart relative contributions of VC accumulation from PVC/ CPVC piping and chlorine-dependent reactions.

\section{Introduction}

1.1. PVC pipe use in drinking water delivery

As drinking water distribution system lines are replaced in the United States at a cost of $\$ 250$ billion over the next few decades, research is needed on the strengths and limitations of the materials that will be installed ((AWWA) 2001). Polyvinyl chloride (PVC) piping is popular due to its relatively low cost, structural strength, ease of installation, and corrosion-resistant properties (Al-Malack and Sheikheldin, 2001). It is currently estimated that $69 \%$ of the piping used in the main drinking water distribution system is plastic, and the majority of the plastic pipe is PVC (Burn, 2005). During the 
Walter, R.K., P. Lin, M. Edwards, and R.E. Richardson (2011), Investigation of factors affecting theaccumulation of vinyl chloride in polyvinyl chloride piping used in drinking water distributionsystems, Water Research (45), 8, doi: 10.1016/j.watres.2011.02.016.

manufacturing of PVC, chlorine and ethylene are combined to create ethylene dichloride, which is converted into vinyl chloride (VC) monomers through a cracking process before polymerization to PVC (Saeki and Emura, 2002). Additionally, chlorinated PVC (CPVC), which is PVC that has been chlorinated via a free radical chlorination reaction and the application of heat, is commonly found in hot water drinking systems and residential homes ((ATSDR) Sept. 2004).

\subsection{Vinyl chloride monomer in PVC pipe}

There have been reports that residual VC monomer in the pipe matrix of the PVC/CPVC piping can be released into air or drinking water (Sano et al., 2001). VC is a known human carcinogen and is regulated by the Environmental Protection Agency (EPA) with a maximum contaminant level (MCL) of $2.0 \mathrm{mg} / \mathrm{L}$ and an MCL-goal (MCLG) of $0 \mathrm{mg} / \mathrm{L}$ in water for potable water (Flournoy and Monroe, 1999). Vinyl chloride concentrations well above the EPA's MCL were reported in stagnant PVC pipe lines in Kansas, Missouri, Texas, and Arkansas ((MDNS), 2006; Flournoy and Monroe, 1999). Additional studies have detected VC levels above the EPA's MCL at $14 \mathrm{mg} / \mathrm{L}$ in PVC pipe manufactured before 1977 (Flournoy and Monroe, 1999; The Vinyl Institute and Uni-Bell PVC Pipe Association, 1994). While modifications to the manufacturing process in 1977 drastically reduced the VC monomer residual in US-manufactured pipe, little work exists that examines the leaching of VC into water from modern US PVC/CPVC pipes - particularly as the pipe ages. Recent work in Saudi Arabia has been performed indicating that static unplasticized PVC (uPVC) accumulates 2.3 $\mathrm{mg} / \mathrm{L}$ of $\mathrm{VC}$ over 14 days when exposed to ultraviolet radiation (Al-Malack, 2004), $2.5 \mathrm{mg} / \mathrm{L}$ of VC over 30 days when exposed to temperatures of $45^{\circ} \mathrm{C}$ (Al-Malack et al., 1999), 2.0-2.1 mg/L of VC in both raw groundwater and chlorinated drinking water (Al-Malack et al., 1999), and $2.5 \mathrm{mg} / \mathrm{L}$ of VC over 30 days when exposed to direct solar radiation (Al-Malack and Sheikheldin, 2001); however, all of these analyses used locally manufactured pipes from Saudi Arabia. Another study with Japanese pipe (unknown manufacturer and production date) found that static PVC pipes filled with deionized water or phosphate buffer did not accumulate detectable VC over a three day period (detection limit in $\mathrm{mg} / \mathrm{L}$ range), but that segments sealed in serum vials did produce detectable VC at more than 50 $\mathrm{mg} / \mathrm{L}$ (Ando and Sayato, 1984). Finally, an Italian study looking at the migration of $\mathrm{VC}$ into drinking water bottled in locally obtained plasticized PVC found that VC accumulated at a rate of $1 \mathrm{ng} / \mathrm{L} /$ day (Benfenati et al., 1991).

\subsection{Study objectives}

The objectives of this study were to compare the accumulation of VC from new pipe reactors from different US manufacturers and different PVC formulations (PVC vs. CPVC) over periods from $4 \mathrm{~h}$ up to 2 years and to understand the effects of aging, biofilm coverage, and chlorine residual on VC levels. Laboratory studies were performed by creating static pipe reactors using new PVC/CPVC from different manufacturers. Likewise, in-use piping segments aged for 2, 15, and 25 years were procured and tested. Finally, copper piping typically used in water distribution systems was tested, eliminating the contribution of VC via chemical leaching from plastic piping. Analyses of the tap water of local homes was also conducted to determine which factors led to detectable VC levels at the tap.

\section{Materials and methods}

\subsection{Static pipe reactors}

Various $3 / 4$ " diameter PVC, CPVC, and copper pipe types obtained from different manufacturers, or from in-use drinking water lines, were cut into $6^{00}$ segments. Before use, all new pipes were rinsed with three changes of water in accordance with NSF 60 standards. All pipes obtained were NSF PW certified. For aged piping, pipe segments were maintained full of water and kept in the dark until the time of the experiment. To remove biofilms, a sterile scraper (Falcon) was used to scrape biofilm from the walls, and tap water was used to rinse the scraped surface. One end of the reactor had a fitted cap, of the same pipe material, glued onto it using Miller Stephenson Epoxy 907 two to three days before the actual experiment. A hole was drilled into the end of the second cap, and a $20 \mathrm{~mm}$ blue butyl rubber septum (Bellco Technology) was glued in place several days before the start of the experiment. The static reactors were $90 \%$ filled with cold, laboratory tap water (chlorinated or dechlorinated) - leaving $10 \%$ headspace to allow gas sampling. After sealing the caps and ensuring that no air bubbles formed in the epoxy, the reactors were allowed to dry for at least $2 \mathrm{~h}$ before sampling. All reactors were incubated at room temperature in the dark during the experiment. One milliliter gas samples were removed to monitor $\mathrm{VC}$ over time and $1 \mathrm{~mL}$ of room air was then injected to avoid the creation of a vacuum in the reactors. VC recovery controls were created by spiking known amounts of VC into subsets of reactors.

\subsection{Water characteristics}

For all studies performed, cold, laboratory tap water, from Cornell University's Water Filtration Plant (CU-WFP), was employed. The chlorine residual was measured using a Hach Chlorine Test Kit. Total chlorine residual was consistently between 0.55 and $0.7 \mathrm{mg} / \mathrm{L}$, while the free chlorine residual was constantly between 0.5 and 0.6 $\mathrm{mg} / \mathrm{L}$. Other characteristics of the source water reported by the CU-WFP were as follows: $\mathrm{pH}=6.9$; alkalinity $=128 \mathrm{mg} / \mathrm{L}$ as $\mathrm{CaCO}_{3}$; total organic carbon $=2.1 \mathrm{mg} / \mathrm{L}$; turbidity $=0.07$ NTU. During all experiments, a $500 \mathrm{~mL}$ beaker was filled with water, tested for chlorine, and then used to fill all the reactors in order to ensure the same water in all reactors. For the dechlorinated water, sodium thiosulfate was employed to neutralize the total chlorine in the samples. A $4.03 \times 10 \sim 4 \mathrm{M}$ stock solution was created and a stoichiometric weight ratio of sodium thiosulfate per $\mathrm{mg} / \mathrm{L}$ of residual chlorine of $0.556 \mathrm{mg} / \mathrm{mg}$ was used based on Metcalf and Eddy's standard for dechlorination (Burton et al., 2002). Residual chlorine testing after dechlorination consistently indicated $0.0 \mathrm{mg} / \mathrm{L}$ of both free and total chlorine. Samples of all experimental runs were preserved in glass vials. 
Walter, R.K., P. Lin, M. Edwards, and R.E. Richardson (2011), Investigation of factors affecting theaccumulation of vinyl chloride in polyvinyl chloride piping used in drinking water distributionsystems, Water Research (45), 8, doi: 10.1016/j.watres.2011.02.016.

\subsection{Analytical techniques}

2.3.1. VC measurements

$V C$ concentrations in pipe reactors were measured using gas chromatography with either a flame ionization detector (GC- FID) or a mass spectrometer (GC-MS). Concentrations of VC in water were calculated from gas phase concentrations using Henry's Law constant and the relative volumes of the aqueous and gas phases.

2.3.1.1. GC-FID. A gas tight syringe was used to inject $1000 \mathrm{~mL}$ of headspace gas into a Perkin Elmer Autosystem GC-FID with a 60/80 Carbopack B Column (Supelco custom 052300 phase, 1\% SP-1000, $8^{\prime}$ $\mathrm{x} 1 / 8$ "). Vinyl chloride standards were prepared by injecting known amounts of VC (99.5\%, Matheson Gas Product Inc.) into $14.6 \mathrm{~mL}$ serum bottles with a PTFE-coated septum and crimp cap. Headspace analysis was carried out, and the data integrator gave peak area values, which were used to create a standard curve. The temperature schedule in the column was $70{ }^{\circ} \mathrm{C}$ for 4 min, ramping by $30{ }^{\circ} \mathrm{C}$ per minute to reach a final temperature of $190^{\circ} \mathrm{C}$, and holding at $190^{\circ} \mathrm{C}$ for $4 \mathrm{~min}$. The FID was held at a constant temperature of $130{ }^{\circ} \mathrm{C}$, and the gas flowrates were $45 \mathrm{~mL} / \mathrm{min}$ and $450 \mathrm{~mL} / \mathrm{min}$ for hydrogen (H2) and air, respectively. The limits of quantification (LOQ) and detection (LOD) were taken to be concentrations whose signal was ten times and three times the standard deviation of the baseline signal, respectively. The LOQ for the GC-FID was found to be 95 ng/L (ppt) in water. Any signal between these two limits was deemed "detectable, but not quantifiable" (DNQ), while signals below the LOD were deemed "below the detection limit" (BDL).

2.3.1.2. GC-MS. In order to obtain a lower detection limit, a Hewlett-Packard GC, 5890 Series II, was coupled to a Hewlett-Packard MS, 5971 Series to analyze VC according to EPA method 524.2 (EPA, 1995). The mass selective detector was operated at an electron energy and detector voltage of $70 \mathrm{eV}$ and $2000 \mathrm{~V}$, respectively. The column was initially held at $80^{\circ} \mathrm{C}$ for $1 \mathrm{~min}$, ramped by $10^{\circ} \mathrm{C}$ per minute to $190^{\circ} \mathrm{C}$, and held at $190{ }^{\circ} \mathrm{C}$ for an additional minute. The select-ion monitoring mode was used in order to obtain the highest analytical sensitivity. Primary and secondary quantification ions were used with the following $\mathrm{m} / \mathrm{z}$ values: 62 (corresponding to ${ }^{35} \mathrm{Cl}$ ) and 64 (corresponding to ${ }^{37} \mathrm{Cl}$ ) (EPA, 1995). The GC-MS method limit of detection (LOD) was found to be $1.8 \mathrm{ng} / \mathrm{L}$, with a limit of quantification (LOQ) of $6.0 \mathrm{ng} / \mathrm{L}$. Subsamples were sent to a certified laboratory for quality assurance of the GC-MS method. VC levels were within $30 \%$ of the values reported by the certified laboratory.

\subsection{Field samples}

Field samples from the Ithaca, NY area were collected from different residents' tap water. Where possible, two water samples were collected in every house: the source water before the PVC/CPVC pipes (well, lake, or municipal clear wells) and also the tap water from locations downstream of runs of PVC/CPVC pipes. Samples were collected by completely filling a $160 \mathrm{~mL}$ serum bottle and immediately sealing with a PTFE-coated septum and crimp cap. After the samples were brought back to the lab (within $12 \mathrm{~h}$ ), a headspace was created by injecting $10 \mathrm{~mL}$ of air into the bottle and then removing 10 $\mathrm{mL}$ of liquid. The bottle was allowed to equilibrate at room temperature for at least $1 \mathrm{~h}$, followed by a headspace analysis for VC. In all of the houses sampled, a "first flush" sample was taken after 8-12 h of overnight stagnancy in the PVC/CPVC. In homes where non-PVC/CPVC fittings linked the PVC/CPVC lines and the tap, enough water was flushed to clear the line of water that sat in those non- PVC/CPVC fittings. Additionally, in a subset of sampling locations, a second sample was taken after flushing the lines with at least 1.5 times the volume of the PVC/CPVC lines. This allowed access to water that sat overnight in pipes upstream of the PVC/CPVC lengths.

\subsection{Epoxy negative controls}

To test whether the Epoxy could contribute to the VC signal, approximately $2 \mathrm{~g}$ of epoxy was placed in a $14.6 \mathrm{~mL}$ tube and crimp capped immediately. Headspace samples were analyzed by GC-MS for $\mathrm{VC}$ using the same method as used for the pipe reactors.

\subsection{Chlorine tests}

For the chlorine tests, the free chlorine test kit (HACH kit Model $\mathrm{CN}-66$ ) with the long path viewing adapter was used to measure free chlorine concentrations. A control was set up in a $160 \mathrm{~mL}$ serum bottle with $145 \mathrm{~mL}$ of tap water. This serum bottle was crimp capped and incubated alongside the pipe reactors at room temperature in the dark.

\subsection{Statistical analysis}

Two sample, Student t-tests, assuming unequal variances, were used for statistical analysis. Also, levels that were DNQ, were taken to be at half the LOQ $(3.0 \mathrm{ng} / \mathrm{L}$ for the GC-MS and $95 \mathrm{ng} / \mathrm{L}$ for the GC-FID), while levels that were BDL, were taken to be zero.

\section{Results}

Any samples that revealed levels of VC that were DNQ are depicted at one half the LOQ, and BDL are shown at zero (or as black triangles) in the figures that follow. Standard curves run over a time span of two years had coefficients of variation of 0.16 and 0.04 for the GC-FID ( $n=3)$ and GC-MS ( $=2)$ methods, respectively. All epoxy controls had VC levels BDL by GC-MS on the first day, and after four months.

\subsection{Vinyl chloride accumulation in new pipe}

3.1.1. Long term study with new schedule 40 PVC

The long term trend of VC measurements made on triplicate PVC reactors filled with chlorinated tap water can be seen in Fig. 1.

$\mathrm{VC}$ concentrations in the reactors were below the detection limit of the GC-FID, until the 63rd day. VC levels reached approximately $130 \mathrm{ng} / \mathrm{L}$ after one year and eventually reached 
Walter, R.K., P. Lin, M. Edwards, and R.E. Richardson (2011), Investigation of factors affecting theaccumulation of vinyl chloride in polyvinyl chloride piping used in drinking water distributionsystems, Water Research (45), 8, doi: 10.1016/j.watres.2011.02.016.

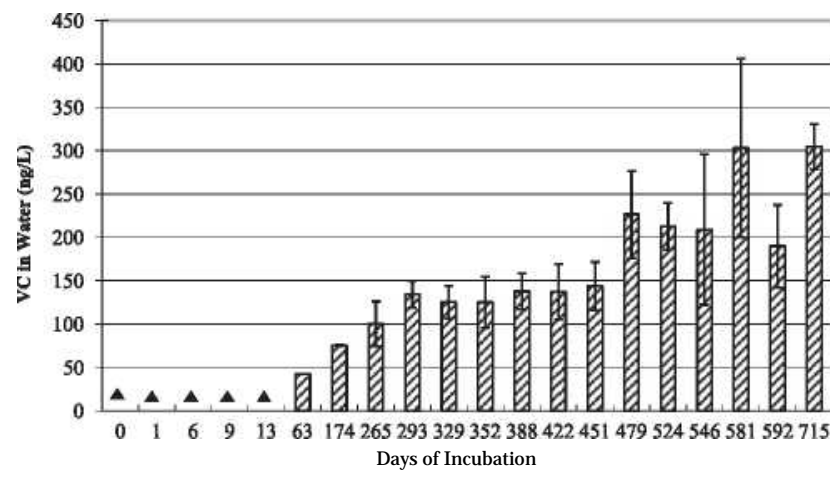

Fig. 1 - Time course of VC concentration found in new Schedule 40 PVC filled with chlorinated tap water. Error bars represent standard error across triplicate reactors and black triangles indicate values below the detection limit (BDL) of the GC-FID. All samples were measured with the GC-FID (LOQ $=95 \mathrm{ng} / \mathrm{L}$ ), except for the $715^{\text {th }}$ day where the GC-MS was used $(\mathrm{LOQ}=6 \mathrm{ng} / \mathrm{L})$.

a value of over $300 \mathrm{ng} / \mathrm{L}$ on the 581st day. On the 715th day, the improved method of the GC-MS corroborated a value of just over $300 \mathrm{ng} / \mathrm{L}$ in water. To estimate losses from the pipe reactors via leaking, control reactors were spiked with VC at $330 \mathrm{ng} / \mathrm{L}$ and 180 $\mathrm{ng} / \mathrm{L}$. These showed expected levels of VC after nine months.

3.1.2. Short term studies on PVC/CPVC pipes from different manufacturers

To better understand VC accumulation on time frames more relevant to consumer usage, repeat studies were conducted with a VC method with improved detection limits (GC-MS method). In the various Schedule 40 PVC reactors, quantifiable VC did not show up until the 29th hour of the experiment (Fig. 2a). By the 101st hour of the experiment all of the samples had detectable VC with concentrations varying from 9.3 to
$24 \mathrm{ng} / \mathrm{L}$, with the highest concentration in water contained in manufacturer A's piping ( $24 \mathrm{ng} / \mathrm{L}$ and $19 \mathrm{ng} / \mathrm{L}$, for the two pipe replicates). As seen in Fig. 2, Manufacturer A's piping accumulated more $\mathrm{VC}$ than the other piping manufacturers.

Two types of new CPVC were tested: Schedule 80 CPVC (from manufacturers A, B, and C) and SDR11 CPVC (from manufacturer E) (Fig. 2b). While the VC levels after $101 \mathrm{~h}$ were similar in all cases to the Schedule 40 PVC, the CPVC reactors showed faster accumulation at early time points (SDR11 CPVC shown in Fig. 4). At $4 \mathrm{~h}$, the SDR11 CPVC reactors $(\mathrm{n}=5)$ were already at $7 \mathrm{ng} / \mathrm{L} \mathrm{VC}$, and 2 of the 3 types of Schedule 80 CPVC were above the GC-MS detection limit. At the $101 \mathrm{~h}$ time point, all new reactors, regardless of formulation and manufacturer, showed VC levels between 11 and $25 \mathrm{ng} / \mathrm{L}$. As with PVC, there was a slight trend in the Schedule 80 CPVC by manufacturer at the $101 \mathrm{~h}$ time point with manufacturer $\mathrm{A}$ $>\mathrm{B}>\mathrm{C}$.

\subsection{Aged pipe with and without biofilm}

To investigate the effects of pipe aging and biofilm coverage on VC accumulation, three different aged pipes were procured and used to establish aged pipe reactors: 1) laboratory-aged 2-year old Schedule 40 PVC pipe (manufacturer A); 2) 15-year old schedule 80, gray PVC piping extracted from the lunchroom line of the City of Ithaca Water Treatment Plant (IWTP) (originally from manufacturer D); 3) 25-year aged, SDR11, CPVC piping extracted from a consumer's home (originally from manufacturer E). Subsets of pipe were scraped to remove biofilms. Results from triplicate reactors filled with chlorinated tap water are shown in Fig. 3. For the 2-year old Schedule 40 PVC (Fig. 3a) and the 25-year old SDR11 CPVC (Fig. 3c), the VC accumulation slightly decreased or increased, respectively, in the presence of the biofilm at the end of the time course; however, all reactors with the biofilm intact behaved similarly to the new pipe (Fig. 2, Manufacturer A and Fig. 4, respectively) with similar ranges of VC concentrations after several days.

The 15-year old Schedule $80 \mathrm{CPVC}$ pipe showed the most surprising results. Within $2 \mathrm{~h}$, as seen in Fig. $3 \mathrm{~b}, \mathrm{VC}$ in both

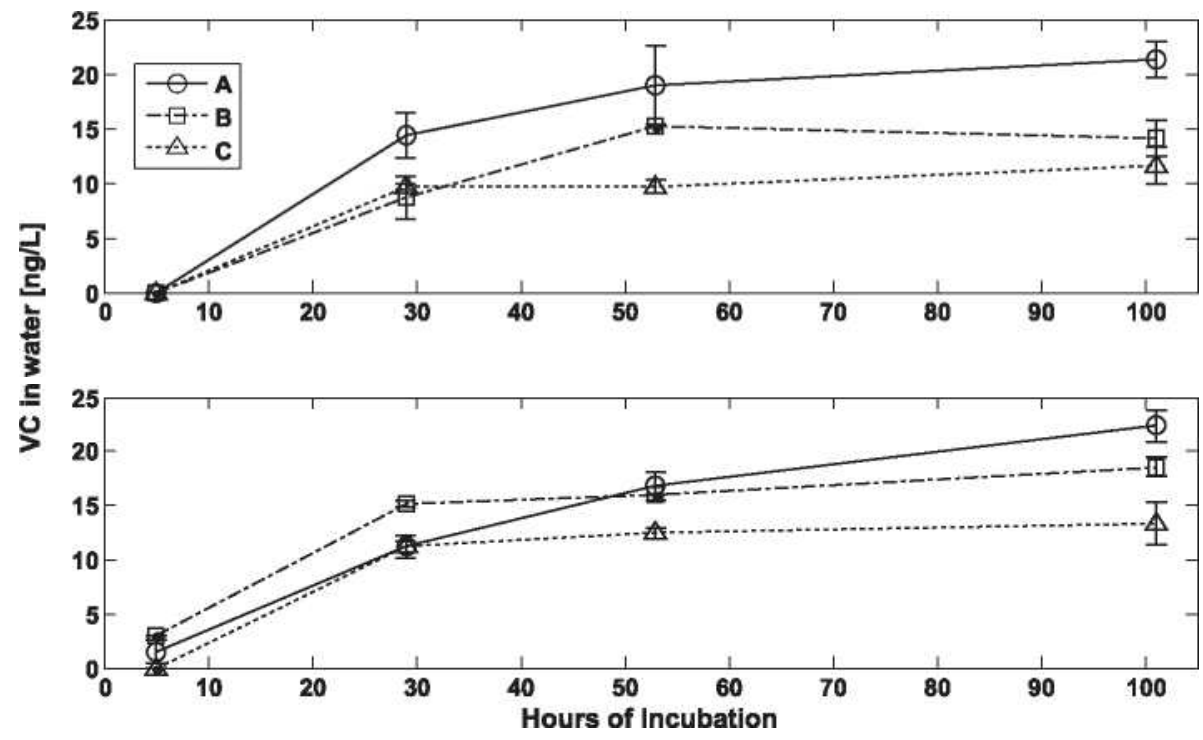

Fig. 2 - Time course of VC in new, Schedule 40 PVC (top panel) and new, Schedule 80 CPVC (bottom panel) with chlorinated water. Error bars show standard error across triplicate reactors. The LOQ for the GC-MS was $6.0 \mathrm{ng} / \mathrm{L}$. 
Walter, R.K., P. Lin, M. Edwards, and R.E. Richardson (2011), Investigation of factors affecting theaccumulation of vinyl chloride in polyvinyl chloride piping used in drinking water distributionsystems, Water Research (45), 8, doi: 10.1016/j.watres.2011.02.016.
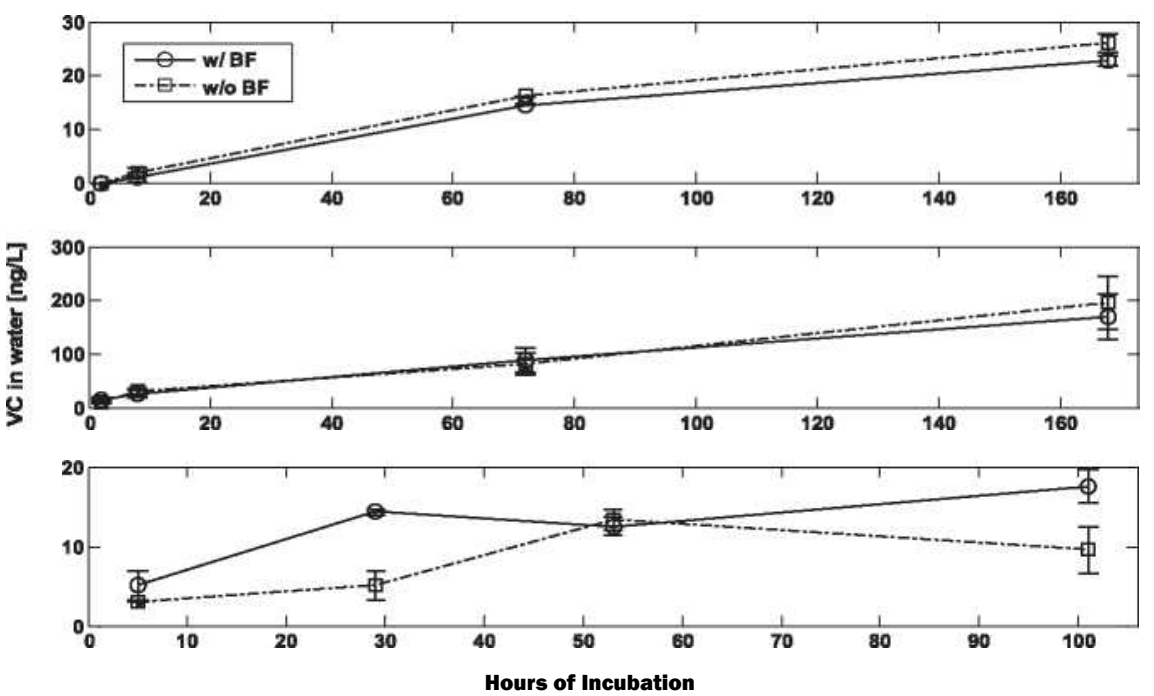

Fig. 3 - Time course of VC in different types of aged piping with biofilm intact versus biofilm scraped. Solid black lines with triangles denote piping with the biofilm intact, dashed-dotted lines with squares indicate piping with the biofilm scraped off, and error bars represent the standard error across triplicate reactors. The LOQ for the GC-MS was 6.0 ng/L. Panel A (top): 2-year aged Schedule 40 PVC; Panel B (middle): 15-year aged Schedule 80 PVC; Panel C (bottom): 25-year aged SDR11 CPVC.

samples were quantifiable, and by the 8 th hour the aged pipe with the biofilm and the aged pipe with the biofilm scraped reached VC levels of 34 and $41 \mathrm{ng} / \mathrm{L}$ in water, respectively. On the 72nd hour, the aged piping showed VC levels slightly higher than that with the biofilm scraped at 119 versus $111 \mathrm{ng} / \mathrm{L}$ in water. However, on the 168th hour, the aged pipe with the biofilm scraped had higher levels of VC at 266 versus $230 \mathrm{ng} / \mathrm{L}$ in water. Yet, these VC levels are considerably higher than any other short term study, and are higher than the VC levels in new Schedule 40 PVC pipe on the 479th day of the long term study ( $227 \mathrm{ng} / \mathrm{L}$ in water). This pipe's surface film had a notable rust color relative to other pipes investigated. Some rust color remained even after scraping. The cross section of

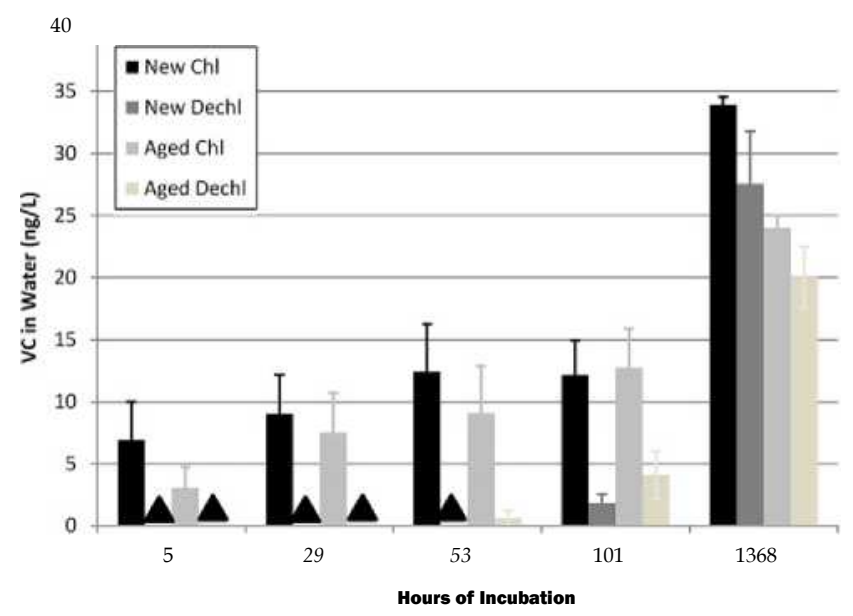

Fig. 4 - Time course of VC in new and aged SDR11 piping with chlorinated and/or dechlorinated water. Error bars show standard error across replicates $(n=2-3)$ and different experiments $(n=2)$ and black triangles indicate values BDL. The LOQ for the GC-MS was $6.0 \mathrm{ng} / \mathrm{L}$. this piping with the biofilm, and with the biofilm scraped, is shown in Supplementary Fig. 1.

\subsection{Field samples}

Water samples from PVC/CPVC-utilizing homes $(n=15)$ around the Ithaca area were collected, and the majority of the samples were below the detection limit for VC; however, several samples contained quantifiable levels of VC. Results are summarized in Table 1. Note that VC levels were measured using a GC-MS for all samples, with the exception of three early samples which were analyzed via GC-FID. These samples are noted in Table 1.

The results indicate that $\mathrm{VC}$ is only showing up at quantifiable levels in small $(<1 ")$, CPVC piping, where municipal water is the water source. Additionally, various pipe lengths produced quantifiable levels of $\mathrm{VC}$, with pipe age having no deterministic effect. The positive detections were from three different municipal distribution systems. Values of VC that were quantifiable ranged from 11 to $23 \mathrm{ng} / \mathrm{L}$ in water, with a mean of $16 \mathrm{ng} / \mathrm{L}$ in water and a median of $13 \mathrm{ng} / \mathrm{L}$ in water. In five homes, two samples were taken: one first flush and a second after at least one-and-a-half holdup volumes of fresh water had flushed the line. Three of the five locations were VC positive, and first flush and post-flushing samples had the same levels of VC $(p=1)$.

\subsection{Effects of chlorine on VC accumulation results}

Following the trends observed in the field sampling results, laboratory tests were conducted to compare results when chlorinated versus dechlorinated tap water was used. The experiment tested both new and 25-year aged SDR11 CPVC pipe. Averages from two replicate studies are plotted in Fig. 4. At all time points, the average $\mathrm{VC}$ levels for pipes receiving 
Walter, R.K., P. Lin, M. Edwards, and R.E. Richardson (2011), Investigation of factors affecting theaccumulation of vinyl chloride in polyvinyl chloride piping used in drinking water distributionsystems, Water Research (45), 8, doi: 10.1016/j.watres.2011.02.016.

\begin{tabular}{|c|c|c|c|c|c|c|c|c|}
\hline Grouping & Pipe type & $\begin{array}{c}\text { Pipe } \\
\text { age (years) }\end{array}$ & $\begin{array}{c}\text { Pipe } \\
\text { length (ft) }\end{array}$ & $\begin{array}{r}\text { Pipe } \\
\text { diameter } \\
\text { (inch) }\end{array}$ & Water source & $\begin{array}{c}\text { \# of Sample } \\
\text { locations }\end{array}$ & \# Positive for VC & $\begin{array}{l}\text { \# Negative for } \\
\text { VC }\end{array}$ \\
\hline 1 & PVC & $<3$ & $<10$ & $>=1$ & Municipal water & 1 & 0 & 1 \\
\hline 2 & PVC & $<3$ & $>50$ & $>=1$ & Well water & 1 & 0 & 1 \\
\hline 3 & PVC & $=3$ & $>50$ & $>1$ & Municipal water & 1 & 0 & 1 \\
\hline $4^{\mathrm{a}}$ & PVC & $4-6$ & $10-50$ & $>=1$ & Lake water & 1 & 0 & 1 \\
\hline 5 & PVC & $4-6$ & $>50$ & $>=1$ & Well water & 1 & 0 & 1 \\
\hline 6 & CPVC & Unknown & $<10$ & $<1$ & Municipal water & 1 & 1 & 0 \\
\hline 7 & CPVC & $4-6$ & $10-50$ & $<1$ & Municipal water & 1 & 1 & 0 \\
\hline 8 & CPVC & $7-10$ & $10-50$ & $<1$ & Well water & 1 & 0 & 1 \\
\hline 9 & CPVC & $11-20$ & $<10$ & $<1$ & Municipal water & 1 & 0 & 1 \\
\hline $10^{\mathrm{a}}$ & CPVC & $11-20$ & $10-50$ & $<1$ & Well water & 3 & 0 & 2 \\
\hline $11^{\mathrm{a}}$ & CPVC & $>20$ & $10-50$ & $<1$ & Well water & 2 & 0 & 3 \\
\hline 12 & CPVC & $>20$ & $10-50$ & $<1$ & Municipal water & 1 & 1 & 0 \\
\hline
\end{tabular}

a One sample for group 4, 10, and 11 were analysed with GC-FID which had a higher limit of quantification of $95 \mathrm{ng} / \mathrm{L}$.

chlorinated water were higher than those receiving dechlorinated water. The results for the chlorinated water repeats were similar to those in Fig. $2 \mathrm{~b}$ (Sch. 80 CPVC) and 3c. However, when dechlorinated water was used, the new pipe did not show detectable VC until the 101st hour. An additional sample taken after 2 months (1368 h) suggested that while much more total VC accumulated by that time, the trend was maintained: reactors with dechlorinated water having lower VC levels than their chlorinated counterparts. Also notable is that the new pipes accumulated more VC after 2 months than aged pipe.

To further investigate the effects of chlorine on VC accumulation, additional tests were done with new, type L copper piping (obtained from manufacturer F) in order to eliminate leaching as a source of VC. Triplicate reactors were filled with chlorinated versus dechlorinated water. As seen in Fig. 5, all samples were below the detection limit (BDL) on the 5th and 29th hours. On the 53rd hour, one of the chlorinated triplicates was detectable but not quantifiable, while the rest of the reactors were BDL. By the 101st hour, all of the chlorinated reactors were detectable with one being quantifiable, while all of the dechlorinated reactors were BDL. Likewise, at the two month time point, all of the dechlorinated reactors were $\mathrm{BDL}$, while two of the triplicate chlorinated water reactors showed detectable VC (up to $10 \mathrm{ng} / \mathrm{L}$ ). Overall, the levels of VC were significantly lower than in any experiments with PVC/CPVC piping at an equivalent time point.

\subsection{Chlorine residual over time}

Chlorine residual was monitored in replicate reactors (CPVC, copper pipe, and serum bottle control). Supplementary Fig. 2 shows the free chlorine residual trends in the reactors. For copper and CPVC negative control pipes filled with deionized water, the free chlorine residual concentrations were all below the detection limit of the DPD (N,N-diethyl-p-phenyl- ediamine) method (the detection limit of the $\mathrm{HACH}$ kit was $0.04 \mathrm{mg} / \mathrm{L}$ using the long path viewing adapter). The residual free chlorine concentrations in the copper pipes over four days were all below detection limit, suggesting rapid consumption of disinfectant. Free chlorine was present in the
CPVC pipes at the 5th hour but was not detected afterward. For the serum bottle control, the free chlorine levels were 0.3 and $0.1 \mathrm{mg} / \mathrm{L}$ at the 5th and 29th hour, respectively and then were below detection at the 53rd ( 2 days) and 101st hour (4 days).

\section{Discussion}

4.1. New piping and concentrations relative to other studies

Concentrations in the long term study reached $300 \mathrm{ng} / \mathrm{L}$ over nearly a two year time period. An Italian study found that $\mathrm{VC}$ accumulated in plasticized PVC drinking water bottles to levels of around 180 ng/L after 200 days (Benfenati et al., 1991). In the current study, it took between 450 and 479 days to reach $180 \mathrm{ng} / \mathrm{L}$ ( $225 \mathrm{ng} / \mathrm{L}$ after 479 days). Looking at the shorter time period reactors, it is clear that VC accumulates in PVC (Sch. 40) and CPVC (Sch. 80 and SDR11) in the range of $11-25 \mathrm{ng} / \mathrm{L}$ after about four days. There were no statistically significant differences between the types of piping; however, different manufacturers of the same pipe type showed variations. For instance, in PVC, manufacturer $\mathrm{A}$ was greater than both $\mathrm{B}$ $(p$-value $=0.080)$ and $C(p$-value $=0.049)$, while in Sch. 80 CPVC, manufacturer A was greater than $C(p$-value $=0.060)$. This indicates that manufacturing processes in the United States affect the vinyl chloride concentration. Studies done under various conditions on unplasticized PVC (uPVC) produced locally in Saudi Arabia showed much higher $\mathrm{VC}$ levels in the $\mathrm{mg} / \mathrm{L}$ range after several weeks (Al-Malack, 2004; Al-Malack et al., 1999; Al-Malack and Sheikheldin, 2001). Likewise, one Japanese study (Ando and Sayato, 1984) found that static PVC pipe reactors (unknown manufacturer) did not produce VC over a three day period, while an Italian study (Benfenati et al., 1991) found VC accumulated in plasticized PVC at a rate of $1 \mathrm{ng} / \mathrm{L} /$ day. These results highlight that manufacturing processes within the United States and abroad greatly affect VC accumulation, as there may be some factor in the production of the piping that influences residual VC monomer concentrations. This effect of manufacturing 
Walter, R.K., P. Lin, M. Edwards, and R.E. Richardson (2011), Investigation of factors affecting theaccumulation of vinyl chloride in polyvinyl chloride piping used in drinking water distributionsystems, Water Research (45), 8, doi: 10.1016/j.watres.2011.02.016.

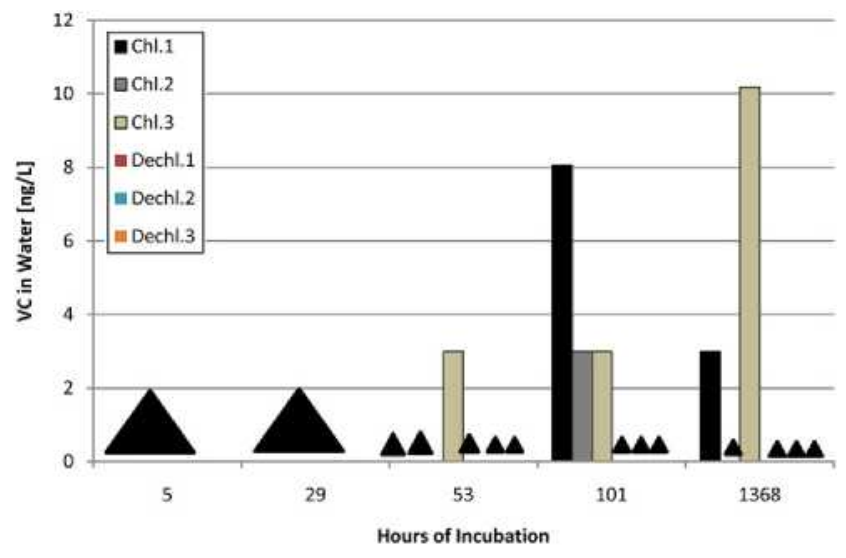

Fig. 5 - Time course of VC in new Type L copper pipe filled with either chlorinated or dechlorinated tap water. Black triangles indicate values BDL. The LOQ for the GC-MS was $6.0 \mathrm{ng} / \mathrm{L}$.

process on VC accumulation is not surprising considering the study of Fluornoy and Monroe on pre-1977 pipes. Both in lab studies and field studies, VC accumulated in drinking water exposed to the PVC at levels well above the MCL of $2 \mathrm{mg} / \mathrm{L}$ (Flournoy and Monroe, 1999).

\subsection{Aging effects}

Aging had no significant effect on the accumulation of VC in the Sch. 40 PVC and SDR11 CPVC over short term accumulation experiments, as the two-year old Sch. 40 PVC and 25-year old SDR11 CPVC showed very similar VC levels to corre- sponding new pipe of the same type at comparable time points over short durations on the order of days (Figures 2a/3a and Figures 3c/4, respectively). However, after two months, SDR11 CPVC showed much higher VC levels in new pipe compared to the aged pipe (new SDR11 CPVC versus aged SDR11 CPVC with biofilm after two months; $\mathrm{p}$-value = 1.65E-05). On the other hand, the 15 year-old Sch. 80 PVC (manufacturer D obtained from the IWTP), showed levels much greater than any other pipe with levels over $200 \mathrm{ng} / \mathrm{L}$ after $168 \mathrm{~h}$. This may be a manufacturer-specific result (we could not find new pipe from the same manufacturer for additional experiments). Alternately, the result could be an effect of the rust-colored (bio) film coating the pipe (see Supplementary Fig. 1). The rust color of the biofilm could indicate iron oxides, which could serve as a catalyst for reactions that promote the accumulation of VC. It is unlikely merely an effect of pipe age given that the 25-year old SDR11 CPVC accumulated a lower VC concentration compared to the new pipe after two months ( $\mathrm{p}$-value $=1.65 \mathrm{E}-05)$, as discussed above.

\subsection{Biofilm effects}

The removal of biofilms from the aged pipes was shown to slightly increase the accumulation of VC in pipe reactors for the Sch. 40 PVC $(\mathrm{p}$-value $=0.100)$ and Sch. $80 \mathrm{CPVC}(\mathrm{n}=1)$ after several days, while the SDR11 CPVC showed higher levels when the biofilm was left intact $(p$-value $=0.063)$ (Fig. 3).
Biofilm effects may be important at longer times as they might provide a barrier to $\mathrm{VC}$ diffusion, or could promote the degradation of VC. Conversely, they can be chlorinated by residual chlorine, leading to production of chlorinated organics that could breakdown into low molecular weight compounds including VC. Further exploration is needed.

4.4. Field and lab evidence of VC as a disinfection byproduct (DBP)

The field study observed detectable VC levels only in tap water from homes on municipal (chlorinated) water supplies. In those homes, the fact that first flush water and water after 1.5 pore-volumes showed statistically indistinguishable VC levels $(p=1.0)$ suggested that residual chlorine may be a contributor to the $\mathrm{VC}$ observations. The follow up lab experiment using chlorinated and dechlorinated water on the SDR11 CPVC with new and aged pipe (biofilm intact) supported this (Fig. 4). While VC in both types of pipe using chlorinated water was detectable after $5 \mathrm{~h}, \mathrm{VC}$ in the dechlorinated reactors was detectable only after $101 \mathrm{~h}$. Even after two months, chlorinated reactors were consistently higher than the dechlorinated reactors for both the new ( $\mathrm{p}$-value $=0.088$ at two months) and aged pipe ( $p$-value $=0.087$ at two months). These results suggest that the chlorine in the tap water, and not simply the piping, may be contributing to the VC accumulation. In the analysis of the copper piping (Fig. 5), the chlorinated reactors accumulated VC at quantifiable levels after $101 \mathrm{~h}(\mathrm{p}$-value $=0.054)$ and two months $(p$-value $=0.10)$ compared to the dechlorinated reactors that never showed detectable VC levels. Since the use of copper eliminates leaching as a source of $\mathrm{VC}$, it is evident from the copper pipe reactors that there is another source of $\mathrm{VC}$ accumulation when residual chlorine $(0.6 \mathrm{mg} / \mathrm{L}$ total chlorine) is present.

The discovery of disinfection byproducts (DBPs) in drinking water has caused public health concerns and become one of the major issues for the drinking water industry. Drinking water DBPs result from the reaction of natural organic matter (NOM) and/or bromide/iodide with disinfectants, such as chlorine or chloramines present in drinking water supplies (Bougeard et al., 2010). Although more than 500 DBPs have been reported in the literature, there are numerous DBPs that have not been identified. It has been estimated that the DBPs currently quantified in drinking water account for no more than $50 \%$ of the total organic halogen (TOX) measured in chlorinated drinking water (Richardson, 2003; Hua and Reckhow, 2008). A significant fraction of TOX formed from chlorine reactions is still of unknown structure. Results from the controlled laboratory experiments with chlorinated and dechlorinated tap water with CPVC and, especially, copper pipes provided the preliminary evidence that VC may be a DBP. Additionally, field samples with VC were all from a municipal (chlorinated) source, and VC levels were the same before and after flushing the lines in the homes. This suggests that VC produced earlier in the distribution system and transported to the home (non-plastic fittings) was a more significant contribution than leaching from the CPVC piping connected to the tap. Finally, free chlorine residual tests (Supplementary Fig. 2) suggest that $\mathrm{VC}$ is not likely a primary DBP, but rather, forms from a secondary reaction with more 
Walter, R.K., P. Lin, M. Edwards, and R.E. Richardson (2011), Investigation of factors affecting theaccumulation of vinyl chloride in polyvinyl chloride piping used in drinking water distributionsystems, Water Research (45), 8, doi: 10.1016/j.watres.2011.02.016.

complex organic matter that gets chlorinated. This secondary DBP hypothesis is supported by the time lag in VC detection seen in the copper piping only after $53 \mathrm{~h}$ (Fig. 5) in comparison to the quick consumption of free chlorine ( $<5 \mathrm{~h}$; Supplementary Fig. 2). More extensive lab studies (with extensive DBP monitoring) as well as field samples from more PVC/CPVC-using systems (and non plastic systems as well) on utility distribution lines (with a chlorine residual) would allow further testing of this claim.

\section{Conclusions}

The purpose of this research was to investigate VC levels encountered in drinking water as a result of the use of PVC/ CPVC pipe. Furthermore, we sought to determine factors affecting the accumulation of VC in PVC/CPVC piping. This research has shown accumulation of VC in PVC/CPVC piping, which is being used increasingly in water distribution systems. Although all values measured in this study are below the EPA's MCL of $2.0 \mathrm{mg} / \mathrm{L}$, many readings, especially at longer times, were quantifiable and, therefore, above the MCL-Goal of $0 \mathrm{mg} / \mathrm{L}$. For new pipe manufactured in the US, long term studies in the lab suggested equilibrium concentrations of about $300 \mathrm{ng} / \mathrm{L}$. In time frames that simulate overnight stagnancy in a home (5-8 h), VC levels varied from below detection ( $<6 \mathrm{ng} / \mathrm{L}$ ) to $20 \mathrm{ng} / \mathrm{L}$, with pipe age and/or manufacturer having some effect. Viewing our results in the context of other studies, considerable differences in VC accumulation can occur across different manufacturers, especially pipe manufactured outside the U.S. and before 1977. Aging effects of pipe were generally negligible, except for an anomalously high level of VC (>200 ng/L in one week) found in one aged pipe with a rust-colored biofilm. Likewise, biofilm effects were mostly small, but need to be further explored at longer times. Field studies found that VC can accumulate in tap water to detectable levels mainly in small diameter (<1") CPVC pipe hooked up to municipal (chlorinated) water, with pipe age and length having no obvious effect. While it has been shown that PVC and CPVC pipe reactors leach VC in short (up to 7 days) and long term (up to 2 years) studies, this research provided preliminary evidence that chlorine may also contribute to VC accumulation via DBP reactions. This is supported by the fact that CPVC reactors accumulated more VC in chlorinated reactors compared to dechlorinated reactors over time, indicating that the chlorine in the water, in addition to leaching from the plastic piping, may contribute to VC accumulation. Likewise, copper pipe tests, which eliminate $\mathrm{VC}$ accumulation via leaching from the plastic pipe, showed detectable VC levels in the chlorinated reactors and not the dechlorinated reactors. Free chlorine residual tests indicate that VC is more likely a secondary, not primary, DBP. Further research needs to be conducted in order to validate this trend and to elucidate reaction mechanisms. Follow up studies need to be tightly controlled with different experimental variables, such as different types of disinfectants, additional studies with metal piping, different total organic carbon levels, and various levels of chlorination, all in an attempt to tease apart the relative contributions from the plastic piping and from chlorine-dependent reactions.

\section{Acknowledgments}

This work was supported by the American Water Works Association Research Foundation (Project \#2991). Additional funding to Ryan Walter was provided through Cornell University's Engineering Learning Initiatives program. Thanks to Kelly Krohn and Mindy Sun for help with initial experiments. We also thank the three local water treatment works (Bolton Point Water Treatment Plant; Ithaca Water Treatment Plant; and Cornell Water Filtration Plant) for their assistance with sampling and providing valuable materials and information.

\section{Appendix. Supplementary material}

Supplementary data related to this article can be found online at doi:10.1016/j.watres.2011.02.016.

\section{R E F E R E N C E S}

(ATSDR), Agency for Toxicity Substances and Disease Registry, 2004. Toxicological Profile for Vinyl Chloride. http:/ / www. atsdr.cdc.gov/toxprofiles/tp20.pdf (accessed 25.04.08.).

(AWWA), American Water Works Association, 2001. Water Industry Technical Action Fund Sponsored Report: Dawn of the Replacement Era: Reinvesting in Drinking Water Infrastructure.

(EPA), Environmental Protection Agency, 1995. Measurement of Purgeable Organic Compounds in Water by Capillary Column Gas Chromatography/Mass Spectrometry Method 524.2, Environmental Protection Agency (EPA).

(MDNS), Missouri Department of Natural Resources, 2006. Controlling vinyl chloride in drinking water distribution systems. Water Protection Program Technical Bulletin June 2006.

Al-Malack, M.H., 2004. Effect of UV radiation on the migration of vinyl chloride monomer from unplasticized PVC pipes. Journal of Environmental Science and Health, Part A-Toxic/ Hazardous Substances \& Environmental Engineering A39 (1), 145-157.

Al-Malack, M.H., Sheikheldin, S.Y., 2001. Effect of solar radiation on the migration of vinyl chloride monomer from unplasticized PVC pipes. Water Research 35 (14), 3283-3290.

Al-Malack, M.H., Sheikheldin, S.Y., Fayad, N.M., Khaja, N., 1999. Effect of water quality parameters on the migration of vinyl chloride monomer from unplasticized PVC pipes. Water Air and Soil Pollution 120 (1-2), 195-208.

Ando, M., Sayato, S., 1984. Studies on vinyl chloride migrating into drinking water from polyvinyl chloride pipe and reaction between vinyl chloride and chlorine. Water Research 18 (3), 315-318.

Benfenati, E., Natangelo, M., Davoli, E., Fanelli, R., 1991. Migration of vinyl chloride into PVC-bottled drinking-water assessed by gas chromatography-mass spectrometry. Food and Chemical Toxicology 29 (2), 131-134.

Bougeard, C.M.M., Goslan, E.H., Jefferson, B., Parsons, S.A., 2010. Comparison of the disinfection by-product formation potential of treated waters exposed to chlorine and monochloramine. Water Research 44, 729-740.

Burn, S., 2005. Long Term Performance Prediction for PVC Pipe; Report Order 91092F, AwwaRF. 
Walter, R.K., P. Lin, M. Edwards, and R.E. Richardson (2011), Investigation of factors affecting theaccumulation of vinyl chloride in polyvinyl chloride piping used in drinking water distributionsystems, Water Research (45), 8, doi: 10.1016/j.watres.2011.02.016.

Burton, F.L., Stensel, H.D., Tchobanoglous, G., 2002. Wastewater Engineering Treatment and Reuse, fourth ed.. Metcalf and Eddy, McGraw Hill, New York City, N.Y.

Flournoy, R.L., Monroe, D., 1999. Health effects from vinyl chloride monomer leaching from pre-1977 PVC pipe. Annual American Water Works Association Conference Proceedings, pp. 1211-1230.

Hua, G., Reckhow, D.A., 2008. DBP formation during chlorination and chloramination: effect of reaction time, $\mathrm{pH}$, dosage, and temperature. Journal American Water Works Association 100 (8), 82-95.

Richardson, S.D., 2003. Disinfection by-products and other emerging contaminants in drinking water. TrAC Trends in Analytical Chemistry 22 (10), 666-684.
Saeki, Y., Emura, T., 2002. Technical progresses for PVC production. Progress in Polymer Science 27 (10), 2055-2131.

Sano, T., Negishi, N., Kutsuna, S., Takeuchi, K., 2001.

Photocatalytic mineralization of vinyl chloride on TiO2. Journal of Molecular Catalysis A: Chemical 168 (1-2), 233-240.

The Vinyl Institute and Uni-Bell PVC Pipe Association, 1994. Investigation of vinyl chloride monomer $(\mathrm{vcm})$ contamination in Doniphan county, Kansas rural water District (RWD) \#5. A Report for U.S. Environmental Protection Agency Office of Drinking Water Washington, DC. 